\title{
Overcoming barriers to biosimilar adoption: real-world perspectives from a national payer and provider initiative
}

\author{
Babette S Edgar, PharmD, MBA, FAMCP; Adam S Cheifetz, MD; Simon M Helfgott, MD; Gideon P Smith, MD, MPH, PhD; \\ Tina Bandekar, RPh; Adam Hoye-Simek, PharmD; YuQian Liu, PharmD, RPh; Rubina M Singh, PharmD, BCPS; \\ Kristina I Fajardo, MS; Jeffrey Carter, PhD; and Laura Simone, PhD
}

\section{SUMMARY}

In response to a published national payer survey indicating striking needs for multistakeholder initiatives to increase biosimilar adoption, a focus workgroup meeting joining payers and providers was conducted in December 2019 in Boston, MA. Before the focus group meeting, a survey was sent to health care providers to collect perceptions about barriers to biosimilar adoption and gather input on best potential strategies for addressing these barriers. The focus group panel consisted of 5 managed care pharmacists and 3 physician experts in rheumatology, dermatology, and gastroenterology, representing large managed care organizations and health care systems in the Boston area.

A clinical moderator facilitated discussions between the payers and providers regarding challenges to biosimilar adoption and poten tial collaborative strategies to overcome these barriers. The focus group participants identified hurdles to biosimilar adoption in 3 major areas: (1) the lack of confidence in biosimilar interchangeability and a need for education about biosimilars, (2) the lack of financial incentives to switch to biosimilars from the reference biologic product, and (3) administrative burdens that impair the prescription of biologics.

Learning from their mutual experiences, the focus group participants formulated action plans to address these barriers. The top strategies recommended by the participants included advancing biosimilar education, facilitating administrative processes related to biosimilar prescriptions, and increasing provider reimbursement while reducing cost sharing to patients receiving biosimilars.
The Biologics Price Competition and Innovation Act (BPCIA) of 2009 accelerated the approval process by the US Food and Drug Administration (FDA) for biologic products shown to be biosimilar to, or interchangeable with, a reference biologic product. In doing so, the BPCIA aims to increase patient access to effective therapies and reduce prices. Indeed, according to a study conducted by RAND Corporation, biosimilars have the potential to lead to substantial health care cost savings, estimated at \$44.2 billion, over 10 years..$^{1-3}$

However, since the first biosimilar approval by the FDA in 2015, adoption of biosimilars in the marketplace has been relatively slow and challenges remain to realize anticipated cost savings. Within the health care chain, various barriers impair biosimilar adoption. Providers who prescribe biosimilars cite concerns for safety and

\section{Author affiliations}

Babette S Edgar, PharmD, MBA, FAMCP, BluePeak Advisors, Dallas, TX; Adam S Cheifetz, MD, Beth Israel Deaconess Medical Center, Boston, MA; Simon M Helfgott, MD, Brigham and Women's Hospital, Boston, MA; Gideon P Smith, MD, MPH, PhD, Massachusetts General Hospital, Boston, MA; Tina Bandekar, RPh, Boston Medical Center Health Plan, Boston, MA; Adam Hoye-Simek, PharmD, Devoted Health, Waltham, MA; YuQian Liu, PharmD, RPh, Magellan Rx Management, Phoenix, AZ; and Rubina M Singh, PharmD, BCPS, Academy of Managed Care Pharmacy, Alexandria, VA Kristina I Fajardo, MS; Jeffrey Carter, PhD; and Laura Simone, PhD, PRIME Education, LLC, Fort Lauderdale, FL.

\section{AUTHOR CORRESPONDENCE:}

Laura Simone, 954.718.6055;

l.simone@primeinc.org

J Manag Care Spec Pharm 2021;27(8):1129-35

Copyright $\odot 2021$, Academy of Managed Care Pharmacy. All rights reserved.

effectiveness (particularly in extrapolated indications), uncertainties about biosimilar interchangeability status, coverage restrictions in formularies that delay reimbursement, and skepticism over the current pricing and 


\section{FIGURE 1 Payer and Provider Perceptions of the Likelihood That Designated Strategies Can Overcome Barriers to Biosimilar Adoption Towards Achieving BPCIA Goals ${ }^{a}$}

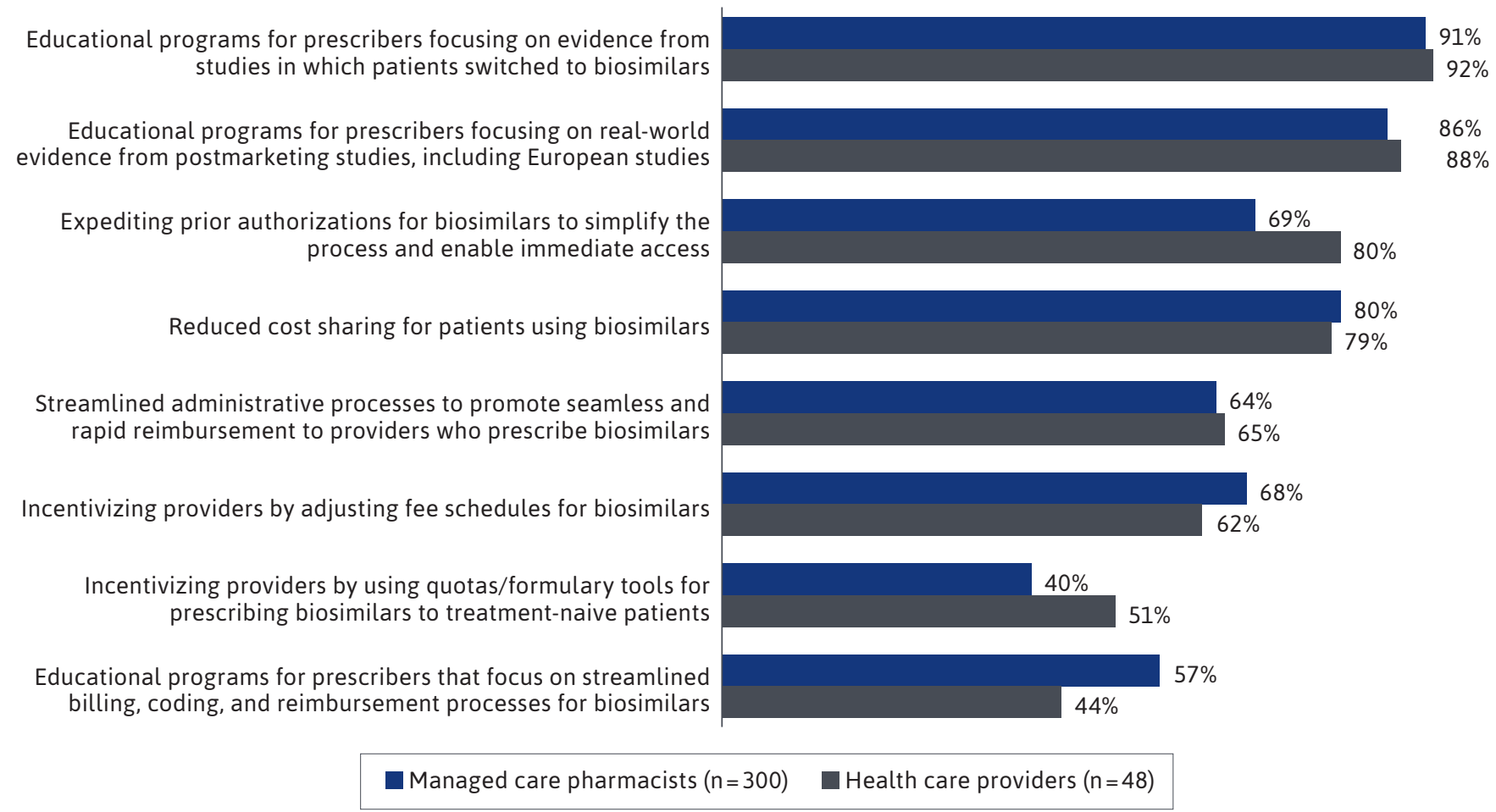

aPooled ratings for 4 (likely) and 5 (very likely) on a 5-point Likert scale. $B P C I A=B i o l o g i c s$ Price Competition and Innovation Act.

expected cost savings of biosimilars. ${ }^{4}$ Therefore, stronger stakeholder support is needed to achieve full benefits from biosimilars.

To better assess these perceptions, in 2019, PRIME Education, LLC (PRIME) and the Academy of Managed Care Pharmacy (AMCP) conducted a national survey to identify top barriers to and potential strategies for biosimilar adoption as perceived by 300 managed care and specialty pharmacy professionals. The seminal results underscored the pressing need for collaborative multistakeholder initiatives involving managed care professionals and providers to overcome formidable barriers to biosimilar adoption. ${ }^{5}$ Multistakeholder and payer-provider workshops can encourage collaboration, resolve persistent issues, and promote joint initiatives among payers and providers.

Recognizing the need for strong collaborative action across pharmacy organizations and other stakeholder groups, PRIME conducted a follow-up national survey to glean insights from community-based providers in various specialties. The survey listed 8 of the 16 strategies that were included in the 2019 managed care pharmacist survey, ${ }^{5}$ and measured providers' ratings of the likelihood that each strategy can overcome barriers towards achieving BPCIA goals (Supplementary Table 1, available in online article). The strategies selected for inclusion in the health care provider survey were those that were perceived to be more directly relevant to providers' roles in clinical care.

Reliability analysis of the 8-item survey was assessed with Cronbach's alpha coefficient, which was calculated at 0.845 , confirming an acceptable level. The survey was sent electronically to expert faculty in PRIME's database who specialize in allergy, dermatology, gastroenterology, oncology, and rheumatology. Forty-eight providers participated in the survey, representing a response rate of $77 \%$ $(N=62)$. Specialties represented were allergy $(n=7)$, dermatology $(n=2)$, gastroenterology $(n=17)$, oncology $(n=15)$, and 
rheumatology $(\mathrm{n}=7)$. Provider disciplines included physicians $(n=39)$, nurse practitioners $(n=1)$, physician assistants $(\mathrm{n}=3)$, and pharmacists $(\mathrm{n}=5)$.

Survey responses from the providers were compared with responses from managed care pharmacists who had been gathered previously. ${ }^{1}$ Figure 1 shows the percentages of respondents from both groups who rated each strategy as being "likely" or "very likely" to overcome barriers to biosimilar adoption. The 2 strategies that received the highest likelihood rating among providers were educational programs for prescribers that (1) focus on evidence from studies in which patients are switched to biosimilars (92\%) and (2) focus on real-world evidence from postmarketing studies (88\%). Strategies that ranked third and fourth in the provider survey were expediting prior authorizations for biosimilars (80\%) and reducing cost sharing for patients using biosimilars (79\%).

In the managed care pharmacist and provider surveys, educational programs were rated as strategies with the highest likelihood of success. "Reduced cost sharing" as a strategy had similar percentage ratings among managed care pharmacists $(80 \%)$ and providers $(79 \%)$. In contrast, a higher percentage of providers (80\%) than managed care pharmacists (69\%) favored "expediting prior authorizations to simplify the process and enable immediate access" as a strategy to facilitate biosimilar adoption.

Aligned with the goal to promote calls to action among multistakeholder groups, PRIME conducted a payerprovider focus group meeting to discuss results of the national managed care pharmacist and provider surveys and stimulate future strategies. The panel consisted of 5 managed care pharmacists and 3 expert physicians in rheumatology, dermatology, and gastroenterology, representing large managed care organizations and health care systems in the Boston area, as well as a clinical moderator to facilitate the discussions. The focus group meeting agenda concentrated on assessing the underlying causes of persistent barriers to adoption of biosimilar therapies for eligible patients with immune-mediated inflammatory diseases and developing collaborative and actionable strategies to overcome these barriers.

The focus group participants largely agreed that transparent discussions between providers, payer groups, and pharmaceutical manufactures were needed. Targeted education for providers about safety, efficacy, and biosimilar interchangeability data was identified as a major component to increase confidence in prescribing these agents. Providers also reported the need to understand the incentives attached to prescribing biosimilars and expected deeper discounts for biosimilars in comparison with the reference product.
Misaligned incentives among stakeholders in the health care industry-including providers, health systems, specialty pharmacies, physicians, and patients-created confusion about clinical and financial benefits of switching to biosimilars, delayed biosimilar adoption, and led to impaired conversations between physicians and patients. We hereby detail the focus group discussion and expand on stakeholders' shared concerns, perceived barriers, and potential strategies.

\section{Biosimilar Educational Initiatives}

As shown in Figure 1, the tethered managed care pharmacist and provider survey results indicate needs for educational initiatives focused on evidence from switching studies (92\% providers, $91 \%$ managed care pharmacists) and real-world evidence from postmarketing studies (88\% providers, $86 \%$ managed care pharmacists) to overcome barriers of biosimilar adoption.

According to the FDA, a biosimilar is a biological product that is highly similar and has no clinically meaningful differences in terms of safety and effectiveness from its reference product. In addition, approvals of biosimilars for use in different indications are made by extrapolation from the reference product. ${ }^{6,7}$ To be considered interchangeable, the BPCIA requires in addition that a biosimilar "produces the same clinical results as the reference product in any given patient." 8,9 This includes the evaluation of the safety and efficacy of switching back and forth between an interchangeable product and a reference product that will be administered more than once. ${ }^{8}$

For biosimilars, postmarketing surveillance studies are pivotal in establishing the safety, efficacy, and immunogenicity profile compared with the reference product. ${ }^{6,8,10}$ To this end, large clinical studies of switching from originator products to biosimilars have been conducted. The Norwegian randomized controlled NOR-SWITCH trial of patients with immune-mediated inflammatory diseases has shown the noninferiority (primary endpoint; disease worsening) of switching from originator infliximab to its biosimilar compared with continued treatment with the originator. ${ }^{1,11}$ Long-term NOR-SWITCH extension studies confirmed noninferiority results of the main trial and comparable safety, efficacy, and immunogenicity over the 78-week study period..$^{10,12}$

Similarly, the efficacy, safety, and immunogenicity of an etanercept biosimilar was confirmed in comparison with its reference product in the randomized controlled EGALITY study of patients with moderate to severe plaque psoriasis who underwent a sequence of 3 treatment switches between the etanercept biosimilar and reference 
product. ${ }^{10,13}$ Postmarketing surveillance studies and longterm real-world safety data should reassure physicians as to the use of biosimilars in practice, yet in surveys, physicians' prescribing confidence remained low. ${ }^{1,7}$

At the focus group meeting, there was consensus regarding the substantial need for provider education about biosimilar use in clinical practice. Providers held positive attitudes and were confident about initiating biosimilars in treatment-naive patients but were conflicted about switching to biosimilars in those maintained on a reference biologic therapy. They felt there were gaps in knowledge about biosimilars, such as product definition, safety and efficacy, role in therapy, and clinical benefit, compared with the reference product. In addition to safety and efficacy data, focus group providers mentioned the need for education on interchangeability and bioequivalence data between biosimilars and reference products.

Managed care clinical pharmacists who interface daily with providers and work with payers to process medication coverage requests are ideally positioned to deliver biosimilar educational activities. Hospital and clinical pharmacists are also experienced in the prior authorization process and possess knowledge about coverage criteria of specialty drugs.

In fact, the focus group providers favored education that was (1) delivered by clinical pharmacists who work at the same institutions, (2) available through a series of grand round or small group presentations, and (3) tailored to different specialty departments with accompanying clinical data for each disease condition. Supplemental educational channels trusted by focus group providers included peer-topeer conversations that occur during national conferences as well as expert meetings.

In addition, the focus group highlighted the importance of identifying community physicians and targeting prescribers of reference biologics as being essential to the design of educational activities suited to their practice needs. Notably, a recent analysis of a commercial medical claims database found greater uptake of the filgrastim biosimilar among office-based providers compared with hospital-based providers, suggesting that, in addition to provider awareness, incentives are key factors influencing biosimilar adoption. ${ }^{14}$

Providers noted the importance of multistakeholder educational forums that convene payers, drug manufacturers, and health care providers to offer the multiple perspectives from those involved in clinical decision making regarding biosimilars. Practicing physicians best understand their patients' medical history and clinical picture and, together with their patients, should be the ultimate decision makers as to treatment. Educational activities valuable to providers are those that invite challenging discussions and contrarian opinions and enable physicians to formulate their own conclusions based on the evidence.

\section{Biosimilar Formulary Management}

Consonant with the views of managed care pharmacists (Figure 1), one of the providers' top strategies to overcome barriers of adoption was "expediting prior authorizations for biosimilars to simplify the process and enable immediate access" (80\% providers survey, 69\% managed care pharmacists). Similarly, the panel agreed that removing administrative burden from prior authorization requirements was necessary to increase biosimilar adoption. Indeed, a recent study of Medicare formulary placement of infliximab and its biosimilars found that when prescription drug plans covered a biosimilar and its reference product, they were placed in the same cost-sharing tier and required prior authorization at the same frequency, providing little incentive for biosimilar adoption. ${ }^{15}$

According to views expressed by the focus group providers, prior authorization requirements pose a significant barrier to adoption of biosimilars with administrative delays and increased use of health care resources acting as considerable deterrents. Furthermore, providers in the focus group expressed the need for more clarity in the approval criteria, sharing that, in addition to providing physicians with the reasons for denial in the response letter, payers should provide information on what documentation was missing from the prior authorization request that would have resulted in an approval.

To increase biosimilar adoption among providers, improving communication with payers was viewed as key. The focus group providers proposed increased transparency related to formulary placement and biosimilar pricing, as well as point of care information about cost savings. For example, real-time benefit checks can give providers and patients point of care information about patient-specific coverage and costs, while also alerting providers about utilization management tools such as prior authorization and identifying alternative therapies. These strategies could drive providers' willingness to prescribe biosimilars and support conversations with patients about biosimilar switches. Furthermore, improved provider understanding about the cost benefits of switching to a biosimilar would increase trust among providers, payers, and patients. ${ }^{16}$

Other favored strategies in both surveys were "incentivizing providers by adjusting fee schedules for biosimilars" (62\% of providers, 68\% of managed care pharmacists) and "reducing cost sharing for patients using biosimilars" (79\% of providers, $80 \%$ of managed care pharmacists), 


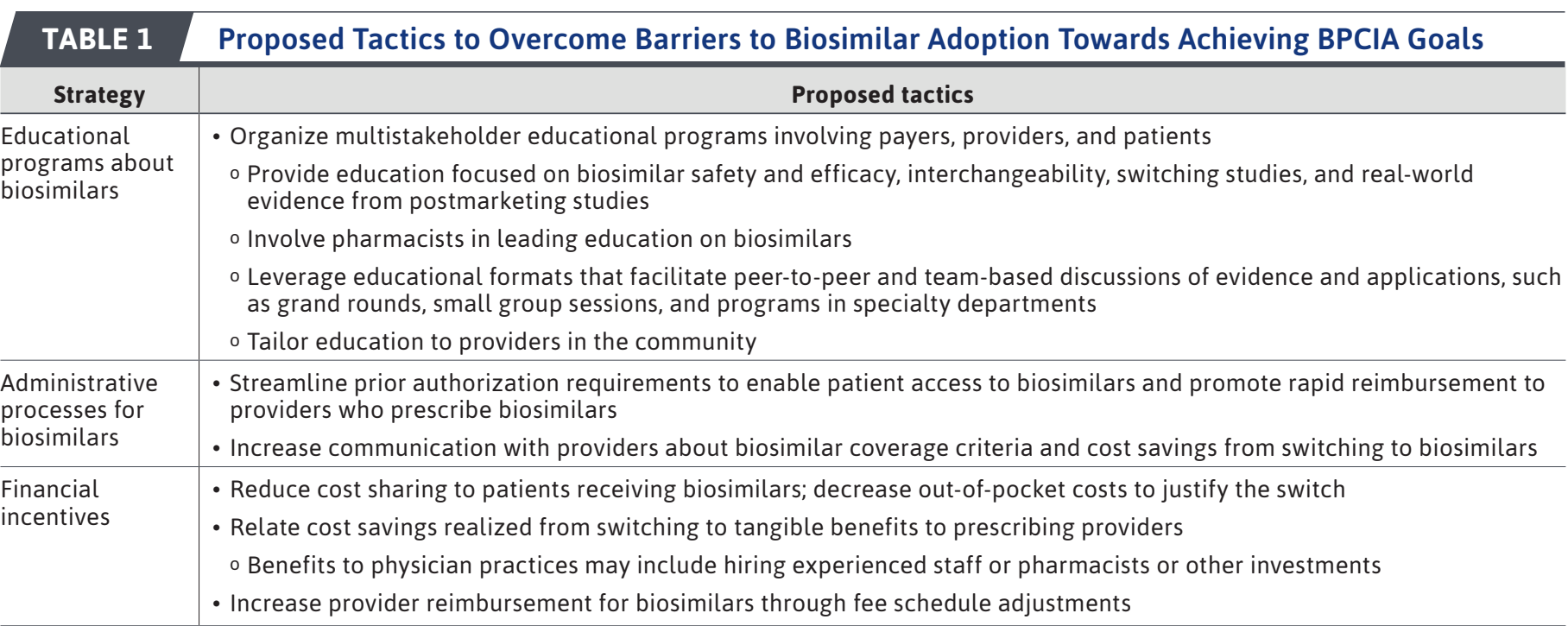

$\mathrm{BPCIA}=$ Biologics Price Competition and Innovation Act.

as has been suggested previously. ${ }^{17}$ In fact, focus group providers believed that switching to biosimilars should be associated with tangible benefits to their practices and patients. Returns from these costs savings to health plans will increase provider reimbursement and can be ultimately reinvested by practices to hire pharmacy, nursing, or social worker staff. Another strategy that providers suggested was a pay-for-performance reward model that increases reimbursement. ${ }^{18}$

Approximately two-thirds of managed care pharmacists and providers rated streamlining administrative processes for reimbursement of biosimilar prescriptions as "likely" or "very likely" to overcome adoption barriers (Figure 1). In this context, focus group physicians expressed concern about long approval times for certain biosimilar infusions products. It is important to note that some biosimilars and reference products, particularly infusions, are managed under the medical benefit or Medicare Part B, whereas others that are self-administered, such as subcutaneous injections, are typically managed under the pharmacy benefit or Medicare Part D. Medicare Prescriptions Drug Plans (PDPs) and pharmacy benefit managers (PBMs) have little formulary decision control over infusions covered under the medical benefit or Part B. Confusion about medical or pharmacy coverage and subsequent erroneous claim submissions may contribute to delays in reimbursement.

In addition, the focus group participants noted that, based on professional observation and experience, biosimilars administered subcutaneously may be formulary-preferred under the pharmacy benefit, or they may have less "red tape" and require less paperwork for prior authorization compared with infusion products under the medical benefit or Part B, which could result in faster approvals of subcutaneous products vs infusions when prescribed for similar indications.

Focus group physicians shared that modifications in preferred formulary agents, such as replacing a reference product with its biosimilar, may create confusion for prescribing providers. To avoid potential confusion, it is important to educate providers about formulary changes and to clarify PBM incentives for making those changes, as well as the resulting benefits for providers and patients. ${ }^{16}$

\section{Payer Real-World Experience in Biosimilar Adoption}

Payers in the focus group panel indicated that most payer organizations tended to adopt a "wait and see" approachobserving results of other payer strategies in forcing a biosimilar switch before deciding on their own strategy. According to the payers' experiences, a successful strategy to increase adoption of a new biosimilar entails careful market preparation that includes engagement of provider networks, negotiations with health systems, and targeted educational initiatives to ensure smooth transitions from a reference biologic to a biosimilar.

One payer participant shared that their company had achieved adoption of biosimilars through a multipronged 
strategy targeting physician providers, health systems, pharmacists, and patients. Discussions with network physicians about a biosimilar switch started several months before the formulary change to reach mutual agreement across stakeholders. Health systems and payers agreed on pricing and reimbursement rates related to the biosimilar switch. Physicians prescribing biosimilars received education about safety, efficacy, and potential cost savings. Community pharmacists that dispensed biosimilars and patients affected by the switch were notified via phone calls and educated about upcoming product changes. There was a 90-day prior notification of the formulary change, and the prior authorization process was removed or accelerated. Furthermore, the payer delivered continuous education about biosimilars during formulary changes throughout and continuously until later phases. Using these targeted initiatives, the payer group achieved a 90\% adoption of biosimilars among their patients.

\section{Conclusions}

Findings from the national provider survey and the payer-provider discussions at the focus group meeting underscored provider concerns about biosimilars and informed tactics for the implementation of strategies to overcome adoption barriers (Table 1). These steps require ongoing collaborative initiatives among multiple stakeholders to optimize use of biosimilars.

One limitation of this study was the missing patient perspective, and future forums should include patients and share their experience with switching to biosimilars. Also, a relatively small number of health care providers participated in the survey, which limits the generalizability of the findings and the conclusions that can be drawn in comparing the payer and provider perceptions. Instead, these findings should be interpreted in the pragmatic context of the educational program in which the survey was conducted, where a key goal was to guide efforts to promote constructive dialogue and collaborative problemsolving among payers and providers.

Another study limitation was that the focus group occurred in a single location in the Boston area and included only rheumatology, dermatology, and gastroenterology experts from academic-based health care systems. Future programs should also include a wide range of providers across regions, specialties, and settings. Nonetheless, the focus group meeting highlighted the importance of closing educational gaps for providers and streamlining payer processes to expedite approvals of biosimilars.

The focus group participants acknowledged misaligned incentives across major players within the biosimilar supply chain and provided tactics to address these issues. This interactive forum discussion and quantitative survey results will continue to shape future collaborativeinitiatives toincreasebiosimilar adoption and patient access to evidence-based therapies.

\section{DISCLOSURES}

The study reported on in this article was part of a continuing education program funded by an independent educational grant that was awarded by Sandoz Inc., a Novartis Division, to PRIME Education, LLC. The grantor had no role in the study design, execution, analysis, or reporting. The Academy of Managed Care Pharmacy (AMCP) received grant funding from PRIME to assist with participant recruitment and content review for the continuing education program. Bandekar, Cheifetz, Edgar, Helfgott, Hoye-Simek, Liu, and Smith received an honorarium from PRIME for serving as faculty for the continuing education program. Cheifetz has received research grants from
Inform Diagnostics and consulting fees from AbbVie, Bacainn, BMS, Grifols, Janssen, Pfizer, Prometheus, Samsung, and Takeda unrelated to this work. Smith has received consulting fees from BoehringerIngelheim, has served as an investigator on industry-initiated trials for AbbVie and Pfizer, and has served as an investigator on investigator-initiated trials for Novartis and Regeneron. Carter, Fajardo, and Simone have nothing to disclose.

\section{ACKNOWLEDGMENTS}

The authors acknowledge Marielle Fares, PharmD, BCGP, MBA, for medical writing support.

\section{REFERENCES}

1. Uhlig T, Goll GL. Reviewing the evidence for biosimilars: key insights, lessons learned and future horizons. Rheumatol. 2017;56(Suppl 4):iv49-iv62.

2. Oskouei ST. Following the biosimilar breadcrumbs: when health systems and manufacturers approach forks in the road. J Manag Care Spec Pharm. 2017;23(12):1245-48. doi: 10.18553/ jmcp.2017.23.12.1245

3. Mulcahy AW, Hlavka JP, Case SR. Biosimilar cost savings in the United States: initial experience and future potential. Rand Heal Q. 2018;7(4):3.

4. Leonard E, Wascovich M, Oskouei S, Gurz P, Carpenter D. Factors affecting health care provider knowledge and acceptance of biosimilar medicines: a systematic review. J Manag Care Spec Pharm. 2019;25(1):102-12. doi: 10.18553/ jmcp.2019.25.1.102

5. Greene L, Singh RM, Carden MJ, Pardo C, Lichtenstein GR. Strategies for overcoming barriers to adopting biosimilars and achieving goals of the Biologics Price Competition and Innovation Act: a survey of managed care and specialty pharmacy professionals. J Manag Care Spec Pharm. 2019;25(8):904-91. doi: 10.18553/jmcp.2019.18412 
6. US Food and Drug Adminstration. Biosimilars action plan: balancing innovation and competition. July 2018. Accessed December 2, 2020. https://www.fda.gov/downloads/ Drugs/DevelopmentApprovalProcess/ HowDrugsareDevelopedandApproved/ ApprovalApplications/Therapeutic BiologicApplications/Biosimilars/ UCM613761.pdf

7. Manolis CH, Rajasenan K, Harwin W, McClelland S, Lopes M, Farnum C. Biosimilars: opportunities to promote optimization through payer and provider collaboration. J Manag Care Spec Pharm. 2016;22(9-a Suppl):S3-S9. doi: 10.18553/ jmcp.2016.22.9-a.s3

8. Lyman GH, Balaban E, Diaz M, et al. American Society of Clinical Oncology statement: biosimilars in oncology. J Clin Oncol. 2018;36(12):1260-65.

9. US Food and Drug Administration. Biosimilars. February 3, 2020. Accessed December 2, 2020. https:// www.fda.gov/drugs/therapeutic-biologics-applications-bla/ biosimilars
10. Ingrasciotta Y, Sultana J, Kirchmayer U, Trifirò G. Challenges in post-marketing studies of biological drugs in the era of biosimilars: a report of the International Society for Pharmacoepidemiology 2019 Mid-Year Meeting in Rome, Italy. BioDrugs. 2019;33(4):345-52.

11. Jørgensen KK, Olsen IC, Goll GL, et al. Switching from originator infliximab to biosimilar CT-P13 compared with maintained treatment with originator infliximab (NOR-SWITCH): a 52-week, randomised, double-blind, non-inferiority trial. Lancet. 2017;389(10086):2304-16.

12. Goll GL, Jørgensen KK, Sexton J, et al. Long-term efficacy and safety of biosimilar infliximab (CT-P13) after switching from originator infliximab: open-label extension of the NOR-SWITCH trial. J Intern Med. 2019;285(6):653-69.

13. Griffiths CEM, Thaçi D, Gerdes S, et al. The EGALITY study: a confirmatory, randomized, double-blind study comparing the efficacy, safety and immunogenicity of GP2015, a proposed etanercept biosimilar, vs. the originator product in patients with moderate-to-severe chronic plaque-type psoriasis. $\mathrm{Br}$ J Dermatol. 2017;176(4):928-38.
14. Chen AJ, Ribero R, van Nuys K. Provider differences in biosimilar uptake in the filgrastim market. Am J Manag Care. 2020;26(5):208-13.

15. Socal MP, Ezebilo I, Bai G, Anderson GF. Biosimilar formulary placement in Medicare Part D prescription drug plans: a case study of infliximab. Am J Health Syst Pharm. 2021;78(3):216-21.

16. Zlatkus A, Bixby T, Goyal K. Considerations for the US health-system pharmacist in a world of biosimilars. Drugs Context. 2020;9:2019-12-1.

17. Falit BP, Singh SC, Brennan TA. Biosimilar competition in the United States: statutory incentives, payers, and pharmacy benefit managers. Health Aff (Millwood). 2015;34(2):294-301.

18. Patel KB, Arantes LH, Tang WY, Fung S. The role of biosimilars in value-based oncology care. Cancer Manag Res. 2018;10:4591-602. 